\title{
Novel method for the isolation of adipose stem cells (ASCs)
}

\author{
T. Rada ${ }^{1,2}$, R. L. Reis ${ }^{1,2}$ and M. E. Gomes ${ }^{1,2 *}$ \\ ${ }^{1}$ Biomaterials, Biodegradables and Biomimetics (3Bs) Research Group, Department of Polymer Engineering, University of Minho \\ Headquarters of the European Institute of Excellence on Tissue Engineering and Regenerative Medicine, Ave Park, Guimarães, Portugal \\ ${ }^{2}$ Institute for Biotechnology and Bioengineering (IBB), PT Government Associated Laboratory, Portugal
}

\begin{abstract}
Adipose stem cells (ASCs) represent a cell population with great potential for tissue engineering applications. Several articles have been published showing the proliferation and differentiation potential, the markers and the wide range of potential applications of these cells. In the majority of these studies the ASCs are isolated using a basic enzymatic procedure, which results in a quite heterogeneous cell population that compromises their proliferation and differentiation. This paper reports the development and optimization of a new isolation/purification method that allows populations of ASCs to be obtained, which significantly reduces (and eventually eliminates) the 'contamination' of other cell types. This method is based on the use of immunomagnetic beads coated with specific antibodies. The first part of the study described here analysed the expression of marker genes for stem cells and the colony-forming unit (CFU) capacity of the cells isolated, while the second part is dedicated to the osteogenic differentiation potential of the isolated cells. The results showed that, using the isolation method based on immunomagnetic beads, it was possible to obtain ASCs and also underline the existence of several subpopulations of stem cells in the adipose tissue. Copyright $\odot 2008$ John Wiley \& Sons, Ltd.
\end{abstract}

Received 2 October 2008; Accepted 23 October 2008

Keywords stem cells; cell isolation; adipose stem cells; tissue engineering; bone tissue engineering; adult stem cells; mesenchymal stem cells; adipose tissue

Adipose tissue presents great potential as a stem cell source for tissue-engineering applications, mostly due to the high availability of this tissue as compared to the other sources, such as the bone marrow. In fact, adipose tissue can be obtained as a 'waste' from a number of surgical procedures and/or harvested from humans through liposuction, which is considered a common and safe (minimally invasive) surgical procedure. Furthermore, adipose stem cells (ASCs) have good differentiation potential, as shown in several studies that have demonstrated the ability of these cells to differentiate into osteoblasts, chondrocytes, endothelial cells and neuronal cells (Castro-Malaspina et al., 1984; Fraser et al., 2006; Goh et al., 2007). The major drawback of adipose tissue as a source of stem cells is contamination

*Correspondence to: M. E. Gomes, 3Bs Research Group, Department of Polymer Engineering, University of Minho, Braga, Portugal. E-mail: megomes@dep.uminho.pt by other types of cells. In fact the adipose stromal fraction is composed by a heterogeneous variety of cells, such as immune cells, haematopoietic stem cells, adipocytes, endothelial cells and fibroblasts (Tholpady et al., 2006), which can negatively affect the proliferation and/or differentiation potential of the ASCs (Quarto and Longaker, 2006; Solchaga et al., 2005).

Most articles found in the literature regarding the use of ASCs describe an isolation technique based on an enzymatic digestion with collagenase, followed by the seeding of the heterogeneous cell populations, which does not solve the problem of 'contamination' as the principle of this isolation method is the property of the ASCs to adhere to the plastic of the culture flasks (Rodbell, 1964, 1966a, 1966b; Van and Roncari, 1977; Van et al., 1976; Marin et al., 1992). The aim of this study was to develop a new isolation method based on immunomagnetic beads that allows the isolation of ASCs, reducing the contamination by other cell types. For 
this purpose, a cell suspension obtained after digestion of rat adipose tissue with collagenase was purified using immunomagnetic Dynal M-450 Epoxy beads (Dynabeads) coated with a different antibody marker for mesenchymal stem cells (patent pending: Rada, Gomes and Reis 2008). Briefly, the beads were coated with either anti-CD49d $\mathrm{Ab}$ (Biogenesis, UK), anti-STRO-1 Ab (Invitrogen, USA) or anti-p75 NGFr Ab (Abcam, UK) antibody, using a concentration of $4 \mu \mathrm{g} / 1 \times 10^{7}$ Dynabeads. The pellet obtained by the enzymatic digestion was resuspended in $0.1 \%$ BSA (Sigma-Aldrich, Germany) in PBS. The Ab-coated Dynabeads were then mixed with the cell suspension and incubated for $30 \mathrm{~min}$ at $4^{\circ} \mathrm{C}$ under gentle stirring. Subsequently, the cell suspension and beads mixture was washed with PBS and BSA and the cells bonded to the Ab-coated Dynabeads were separated from the remainder of the cell suspension using the Dynal MPC magnet (Dynal Biotech, USA). Finally the cells bonded to the Ab-coated Dynabeads were seeded in $75 \mathrm{~cm}^{3}$ cell culture flasks.

Real-time RT-PCRs for CD44, STRO-1, CD105 and CD90 and CFU test were peeformed to characterize the cells isolated using this methodology. Additionally, osteogenic differentiation was studied, culturing the isolated cells for 4 weeks using osteogenic medium. Cells were stained with Alizarin red and osteocalcein and osteopontin gene expression were quantified using real-time RT-PCR.

The results obtained showed that all the cells isolated with immunomagnetic beads coated with the different Abs had colony-forming (CFU) capacity and all expressed CD44, STRO-1, CD105 and CD90 (Table 1). Regarding the osteogenic differentiation, all the rat ASCs isolated expressed osteopontin and osteocalcein (Table 2) and stained positive to Alizarin red.

It was also found that the levels of gene expression and the osteogenic differentiation potentials were different between the different cells isolated with different antibodies. In fact, the subpopulation isolated using immunomagnetic beads coated with STRO-1 was the one that showed the highest stem cell marker gene expression and the highest osteogenic differentiation potential. Using the immunomagnetic beads isolation

Table 1. Gene expression of the cells isolated with the different methods compared to the reference sample (cells isolated with the enzymatic method) used to calculate the $\Delta \Delta \mathrm{Ct}$ (mathematical method to calculate the gene expression); the symbol + ) stands for expression levels higher than the reference sample ( $>1)$; and the symbol - ) stand for expression levels lower than the reference sample $(<1)$

\begin{tabular}{lcccc}
\hline & \multicolumn{4}{c}{ Gene expression } \\
\cline { 2 - 5 } Isolation methods & CD105 & CD44 & CD90 & STRO-1 \\
\hline STRO-1 & + & + & + & + \\
CD49d & - & + & + & + \\
NGFr & - & - & + & - \\
\hline
\end{tabular}

Table 2. Gene expression for osteopontin and osteocalcein of the cells isolated with the different methods compared to the reference sample (cells cultured with basal medium) used to calculate the $\Delta \Delta \mathrm{Ct}$ (mathematical method to calculate the gene expression); the symbol +) stands for expression levels higher than the reference sample $(>1)$; and the symbol -$)$ stand for expression levels lower than the reference sample $(<1)$

\begin{tabular}{lcc}
\hline & \multicolumn{2}{c}{ Gene expression } \\
\cline { 2 - 3 } Isolation methods & Osteocalcein & Osteopontin \\
\hline CD49d & - & + \\
NGFr & - & + \\
STRO-1 & + & + \\
Enzymatic method & - & + \\
\hline
\end{tabular}

method, it was possible to isolate rat ASCs with minor contamination by other cell types, as compared to cells isolated using the enzymatic method. In this study, combination of the isolation method described with the use of different antibody markers for mesenchyamal stem cells allowed us to conclude that the stem cells from adipose tissue constitute a complex population, formed of several subpopulations that present different stem cell marker gene expressions and different osteogenic differentiation potentials.

\section{References}

Castro-Malaspina H, Ebell W, Wang S, et al. 1984; Human bone marrow fibroblast colony-forming units (CFU-F). Prog Clin Biol Res 154: 209-236.

Fraser JK, Wulur I., Alfonso Z., et al. 2006; Fat tissue: an underappreciated source of stem cells for biotechnology. Trends Biotechnol 24(4): 150-154.

Goh BC, Thirumala S., Kilroy G., et al. 2007; Cryopreservation characteristics of adipose-derived stem cells: maintenance of differentiation potential and viability. $J$ Tissue Eng Regen Med 1(4): $322-324$

Marin P, Andersson B., Ottosson M., et al. 1992; The morphology and metabolism of intra-abdominal adipose tissue in men. Metabolism 41(11): 1242-1248.

Quarto N, Longaker MT. 2006; FGF-2 inhibits osteogenesis in mouse adipose tissue-derived stromal cells and sustains their proliferative and osteogenic potential state. Tissue Eng 12(6): 1405-1418.

Rada T, Gomes ME and Reis RL. 2008; Método para obtenção de células estaminais adultas a partir de tecido adiposo. I.N.D.P.I., Portugal. 104164.

Rodbell M. 1964; Metabolism of isolated fat cells. I. Effects of Hormones on Glucose Metabolism and Lipolysis. $J$ Biol Chem 1964; 239: 375-380.

Rodbell M. 1966a; Metabolism of isolated fat cells. II. The similar effects of phospholipase C (Clostridium perfringens $\alpha$-toxin) and of insulin on glucose and amino acid metabolism. $J$ Biol Chem 241(1): 130-139.

Rodbell M. 1966b; The metabolism of isolated fat cells. IV. Regulation of release of protein by lipolytic hormones and insulin. J Biol Chem 1966; 241(17): 3909-3917.

Solchaga LA, Penick K., Porter J.D., et al. 2005; FGF-2 enhances the mitotic and chondrogenic potentials of human adult bone marrow-derived mesenchymal stem cells. J Cell Physiol 203(2): 398-409.

Tholpady SS, Llull R., Ogle R.C., et al. 2006; Adipose tissue: stem cells and beyond. Clin Plast Surg 33(1): 55-62, vi.

Van RL. Bayliss C.E. and Roncari D.A., et al. 1976; Cytological and enzymological characterization of adult human adipocyte precursors in culture. $J$ Clin Invest 58(3): 699-704.

Van RL, Roncari DA. 1977; Isolation of fat cell precursors from adult rat adipose tissue. Cell Tissue Res 181(2): 197-203. 